\title{
Knowledge towards standard precautions among healthcare providers of hospitals in Amhara region, Ethiopia, 2017: a cross sectional study
}

Ayele Semachew Kasa ${ }^{1 *} \mathbb{D}$, Worku Animaw Temesgen ${ }^{1}$, Yinager Workineh², Tadesse Dagget Tesfaye ${ }^{1}$, Sitotaw Kerie ${ }^{1}$, Eden Amsalu ${ }^{2}$ and Solomon Emishaw Awoke ${ }^{3}$

\begin{abstract}
Background: Literatures revealed that healthcare-associated infections are still a great concern in many developing countries including in Ethiopia. Despite the development of detailed guidelines for infection control, they remain as a critical challenge for the public health sectors and the knowledge of standard precautions among healthcare workers in many developing countries is low and not properly applied. Hence, the present study tried to determine the level of knowledge about standard precautions among healthcare workers of Amhara region, Ethiopia.

Methods: Institutional based cross-sectional study was conducted on a randomly selected public hospitals of Amhara region, Northwest Ethiopia from March 01-April 01/2017. A multistage sampling strategy was utilized to select 795 sampled healthcare workers. Data were collected using pretested self-administered questionnaire. The collected data entered using EpiData Version 3.1 statistical software and analyzed using SPSS version 20 statistical package. After using binary logistic regression, multivariable logistic regression analysis used to form the model. Variables which had statistically significant association with the outcome variable $(P<0.05)$ were identified as significant in the multivariable logistic regression analysis.
\end{abstract}

Results: Almost half (49.2\%) of the study participants were female healthcare workers. Three-fourth (74.3\%) of the healthcare workers involved in the current study had good knowledge towards standard precautions. Good knowledge towards standard precautions refers to scoring correct responses to $>60 \%$ of knowledge items from the survey. Year of service (AOR: 0.27, 95\% Cl: 0.16 to 0.44), educational status (AOR: 1.7, 95\% Cl: 1.13 to 2.56) were among the predictor variables. In addition, physicians were 6.97 times more likely to be knowledgeable (AOR: 6.97, $95 \% \mathrm{Cl} 2.42$ to 20.12 ) than laboratory technician/technology counterparts. Study participants working in medical, Gyn/obs, pediatrics wards, and OPD were about 2.23, 4.27, 2.81 and 2.52 times more likely to be knowledgeable than study participants working in surgical ward.

(Continued on next page)

\footnotetext{
* Correspondence: finoteayu24@gmail.com

${ }^{1}$ Department of Adult Health Nursing, College of Medicine and Health Sciences, Bahir Dar University, Bahir Dar, Ethiopia

Full list of author information is available at the end of the article
} 
(Continued from previous page)

Conclusions: Overall, the majority of healthcare workers had good knowledge of standard precautions. But variation in knowledge was detected across healthcare workers by hospital type and ward/units. This may help to design a solution by prioritizing the problem.

Keywords: Infection prevention, Standard precautions, Knowledge, Healthcare workers, Amhara region, Ethiopia

\section{Background}

Standard precautions (SPs) are intended for use to prevent the transmission of infection from one source to another. SPs are intended to protect healthcare providers, patients, and supporting staffs from nosocomial infections and occupational hazards [1, 2]. Healthcareassociated infections (HAIs) are the main cause of morbidity and mortality associated with clinical, diagnostic and therapeutic procedures $[3,4]$. HAIs are not only a threat for healthcare workers (HCWs) but also a threat for service users and patients [5].

HAIs are pathogens that spread from one individual to others through a variety of ways. The most important spreading mechanism of these pathogens is via contaminated hands of the healthcare provider to the other healthcare provider, to patients or attendants of the patients. Fomites will also serve as a reservoir for potentially source of infectious agents like contaminated environmental surfaces, drugs, intravenous solutions or foodstuffs. The most important circumstances that a healthcare provider to be a risky group in any healthcare setting for HAIs are during direct patient care, instrument processing, surgical procedures, healthcare waste disposal, and processing patient care items $[6,7]$.

Different actions have been done tirelessly by the Federal Ministry of Health of Ethiopia to strengthen infection prevention measures. The measures mainly focused on bringing up-to-date information and practical interventions in the area of infection prevention [8]. Despite these efforts, in Ethiopia, the infection prevention activities are low $[9,10]$.

HAIs remain a critical challenge for the public health sectors in many developing countries [11]. Literatures revealed that HAIs are still a great concern in Ethiopian healthcare facilities $[12,13]$. Despite the development of detailed guidelines for infection control, the knowledge of standard precautions among HCWs in many developing countries is low and not properly applied [11, 14]. A study revealed that SPs awareness has not been pronounced among healthcare workers, particularly in developing countries [15]. The Ethiopian Public Health Institute (EPHI) on services availability and readiness assessment informed that health workers must be able to work in a safe environment and must be provided with all the safety training need to carry out their duties. The assessment also revealed that there was a lack of knowledge on the proper utilization of SPs among different healthcare professionals [16].

Having adequate knowledge is a pre-requisite for implementing SPs in healthcare facilities. Poor knowledge about SPs among HCWs is the most common responsible reason for low adherence in implementing SPs in various healthcare facilities [17-19]. Hence, the present study tried to determine the level of knowledge among HCWs working in different healthcare facilities of Amhara region, Ethiopia towards SPs.

\section{Methods}

The study was conducted in public hospitals in Amhara region from March 01-April 01/2017 using crosssectional study design. Amhara region is one of the largest regions in Ethiopia found in the northwest direction. Currently, the region has more than 19 referral, zonal and district hospitals serving the populations of the region and neighboring residents. According to the 2015 Health Sector Development Plan-III (HSDP III) the Ethiopian health care tier system has different health facilities that consists of Referral hospital which serves approximately for 3.5 to 5.0 million, Zonal hospital serves for 1.0 to 1.5 million, and District hospital serves for 60 , 000 to 100,000 population [20].

The current study was carried out at eight randomly selected hospitals: two referral hospitals (Felege Hiwote and Gondar), four zonal hospitals (Debre Birhan, Debre Markos, Debre Tabor, and Dessie) and two district hospitals (Motta and Finote Selam).

HCWs involved in the provision of direct healthcare and those having contact with hospitals' healthcare wastes were included in the study. Moreover, those study participants who are working in different inpatient and outpatient departments of the included hospitals were included.

\section{Sample size determination and sampling procedure}

The sample size of the study was determined by using a single population proportion formula by taking $(P=$ $37.7 \%$ ) of the HCWs who had good knowledge towards standard precautions from a study done in Nigeria [21]. The 95\% confidence interval, 0.5 margins of error, 10\% none -response rate and a design effect of two were considered. Then, we reached at a final sample size of 795 . 
In order to select representative study participants, the total number of HCWs from each selected hospital were obtained. List of HCWs with their current working ward and profession was obtained from each hospital's medical and matron offices. The total sample size was proportionally allocated in each hospital. Then from each hospital a study unit (HCWs) was selected using simple random sampling technique using their names' list.

\section{Data collection}

The data were collected using a structured selfadministered questionnaire. The questionnaire was developed after reviewing different relevant literatures on the subject. It was divided into two parts. Part I: focused on socio-demographic characteristics and Part II: Questions to ascertain the level of knowledge towards standard precautions (Additional file 1).

\section{Data quality and control measures}

The data collection tool developed after extensive literature search majorly from CDC and Ethiopian infection prevention guideline for health facilities [1, 22, 23]. First, the questionnaire was prepared in English and then translated to the local language (Amharic). Finally, the questionnaire was back-translated to the English language to confirm its consistency. To assess the reliability of the questionnaire, a pretest was conducted in $10 \%$ of the calculated sample sizes in Dangila hospital which was not included in the actual study.

Six junior nurses and three senior nurses were recruited as data collectors and supervisor respectively. Before the actual data collection period they received training about the questionnaire and how to approach the respondents. Completeness and clarity of the collected data were checked carefully on a regular basis. Furthermore, questionnaires with significant incompleteness were rejected from the whole analysis.

\section{Operational definitions Scoring of knowledge}

Knowledge was measured by a set of 11 questions. For every correct response, 1 point was given and 0 was given for an incorrect answer. Accordingly, knowledge scores ranged from 0 to 11 .

\section{Good knowledge to SPs}

Those HCWs scored $\geq 60 \%$ out of knowledge assessing questions.

\section{Poor knowledge to SPs}

Those HCWs scored $<60 \%$ out of knowledge assessing questions. The knowledge score of the respondents was dichotomized as described above and this scoring system was also used in earlier studies [24, 25].

\section{Data processing and analysis procedure}

Data entry was done by EPI info 3.5.1 and then transferred to SPSS version 20 statistical software for data cleaning, coding, and analysis. To explain the study population in relation to relevant variables, frequencies and summary statistics were done.

In order to determine the association between independent and dependent variables; multiple logistic regression analysis was performed. Variables with a $P$ value less than or equal to 0.20 in the bivariate model were included in the multivariable logistic regression model. Finally, a $P$-value of $<0.05$ was considered as statistically significant.

\section{Result}

Out of 795 sampled respondents, 765 agreed to participate in this study and from these, 742 participants completed all the questions without missing. As a result, 93.3\% response rate was achieved. From the total six hospitals; 461 (62.1\%) HCWs were from referral hospitals, $214(28.8 \%)$ from Zonal hospitals and 67 (9.0\%) were from district hospitals.

\section{Socio-demographic description of study participants}

Of the total study participants, almost half (49.2\%) were females. The majority (56.5\%) were in the age range of 20-29 years. Regarding marital status, $51.6 \%$ were single whereas only $2 \%$ were widowed.

Concerning to educational status, 54.9\% had bachelor degree whereas $4.3 \%$ were master's degree holders. Professionally, the majority of study participants (55.9\%) were nurses and $2.7 \%$ health officers. From all study participants, $40.3 \%$ had more than 6 years of work experience in the healthcare facilities. From the total study participants, $42.7 \%$ received training on SPs in the last 5 years. Almost one fifth (19\%) of study participants worked at surgical wards and $9.6 \%$ at Pediatrics wards (Table 1).

\section{Overall knowledge of HCW towards SPs}

In the current study, almost three-fourth (74.3\%) of the study participants had good knowledge of standard precaution. Almost $85 \%$ of the study participants replied that adhering standard precautions protect HCWs getting infected from patients. Ninety two percent of the study participants replied that adhering standard precautions protect HCWs while handling infectious waste. More than $80 \%$ of HCWs replied that adhering standard precautions protect HCWs while handling sharp waste (Table 2).

\section{Factors associated with knowledge of study participants towards SPs}

Candidate predictor variables from the bivariate regression model were entered into the multivariable logistic 
Table 1 Socio-demographic characteristics of healthcare workers in Amhara region towards standard precaution, 2017

\begin{tabular}{|c|c|c|}
\hline Variables & Frequency & Percent \\
\hline \multicolumn{3}{|l|}{ Sex } \\
\hline Male & 377 & 50.8 \\
\hline Female & 365 & 49.2 \\
\hline \multicolumn{3}{|l|}{ Age (in year) } \\
\hline $20-29$ & 419 & 56.5 \\
\hline $30-39$ & 271 & 36.5 \\
\hline $40-49$ & 41 & 5.5 \\
\hline$\geq 50$ & 11 & 1.5 \\
\hline \multicolumn{3}{|l|}{ Marital status } \\
\hline Single & 383 & 51.6 \\
\hline Married & 320 & 43.1 \\
\hline Divorced & 24 & 3.2 \\
\hline Widowed & 15 & 2.0 \\
\hline \multicolumn{3}{|l|}{ Educational status } \\
\hline Diploma & 303 & 40.8 \\
\hline Bachelor degree & 407 & 54.9 \\
\hline Master's degree & 32 & 4.3 \\
\hline \multicolumn{3}{|l|}{ Religion } \\
\hline Orthodox & 594 & 80.1 \\
\hline Muslim & 107 & 14.4 \\
\hline Protestant & 33 & 4.4 \\
\hline Others $^{a}$ & 8 & 1.1 \\
\hline \multicolumn{3}{|l|}{ Profession } \\
\hline Nurse & 415 & 55.9 \\
\hline Laboratory & 108 & 14.6 \\
\hline Midwifery & 104 & 14.0 \\
\hline Physician & 95 & 12.8 \\
\hline Health officer & 20 & 2.7 \\
\hline \multicolumn{3}{|c|}{ Work experience (in years) } \\
\hline $1-3$ & 251 & 33.8 \\
\hline $4-6$ & 192 & 25.9 \\
\hline$>6$ & 299 & 40.3 \\
\hline \multicolumn{3}{|c|}{ Training on SP in the last 5 year } \\
\hline Yes & 317 & 42.7 \\
\hline No & 425 & 57.3 \\
\hline \multicolumn{3}{|l|}{ Hospital type } \\
\hline Referral & 461 & 62.1 \\
\hline Zonal & 214 & 28.8 \\
\hline District & 67 & 9 \\
\hline \multicolumn{3}{|l|}{ Ward } \\
\hline Surgical & 141 & 19.0 \\
\hline Medical & 106 & 14.3 \\
\hline Gyn/obs & 119 & 16.0 \\
\hline
\end{tabular}

Table 1 Socio-demographic characteristics of healthcare workers in Amhara region towards standard precaution, 2017 (Continued)

\begin{tabular}{|c|c|c|}
\hline Variables & Frequency & Percent \\
\hline Pedi & 71 & 9.6 \\
\hline OPD & 95 & 12.8 \\
\hline Laboratory & 108 & 14.6 \\
\hline Others $^{b}$ & 102 & 13.7 \\
\hline
\end{tabular}

regression model. Among the nine variables entered into the bivariate model, one variable (training on SP) did not meet the criteria of significance $(p>0.2)$ to enter into the multivariable regression analysis. The multivariable logistic regression analysis showed that educational status, profession, service year, hospital type and ward type were shown to be significant predictors of knowledge towards SPs.

Participants with first-degree educational status were 1.7 times more likely to be knowledgeable than diploma holders (AOR: 1.7, 95\% CI: 1.13 to 2.56). Regarding the professional category, nurses were 3.65 times more likely to be knowledgeable than their laboratory technician/ technology counterparts (AOR: 3.65, 95\% CI: 1.85 to7.18). Whereas, compared to laboratory technician/ technology counterparts, physicians were 6.97 times more likely to be knowledgeable (AOR: 6.97, 95\% CI 2.42 to 20.12).

Concerning to service year, study participants who served for more than 6 years were $73 \%$ less likely to be knowledgeable than study participants who served for less than 3 years (AOR: 0.27, 95\% CI: 0.16 to 0.44 . HCWs from zonal hospitals were 1.93 times more likely to be knowledgeable than study participants working at referral level hospitals (AOR: 1.93, 95\% CI 1.18 to 3.14). Study participants working at medical, Gyn/obs, pediatrics wards, and OPD were about 2.23, 4.27, 2.81 and 2.52 times more likely to be knowledgeable than study participants working at surgical ward (AOR: 2.23, 95\% CI: 1.17 to 4.26 ), (AOR: 4.27, 95\% CI: 1.97 to 9.23), (AOR: 2.81, 95\% CI: 1.31-6.03) and (AOR: 2.52, 95\% CI: $1.25-5.07$ ) respectively (Table 3 ).

\section{Discussion}

Nosocomial infections and occupational hazards increase patients' morbidity, mortality, length of hospital stay, and related treatment cost [26]. Hence, knowledge of standard precautions is important in preventing the occurrence of HAIs in healthcare settings. During patients' care, it is thus of the highest importance for HCWs to have the knowledge of infection prevention and control measures [27]. This study aimed to determine the level 
Table 2 Healthcare workers knowledge regarding standard precautions in healthcare facilities of Amhara region, Northwest Ethiopia, $2017(n=742)$

\begin{tabular}{|c|c|c|}
\hline Items & Number $(n)^{a}$ & Percent (\%) \\
\hline All patients, healthcare workers and communities in healthcare facilities are at risk of health care related infection & 582 & 78.4 \\
\hline Standard precautions should be applied to all patients regardless of their infectious status & 621 & 83.7 \\
\hline Adhering standard precautions protect HCWs getting infected from patients & 635 & 85.6 \\
\hline Adhering standard precautions protect patients getting infected from HCWs & 530 & 71.4 \\
\hline Adhering standard precautions prevent mutual transfer of infection among patients & 518 & 69.8 \\
\hline Adhering standard precautions protect HCWs while handling infectious waste & 685 & 92.3 \\
\hline Adhering standard precautions protect HCWs while handling sharp waste & 611 & 82.3 \\
\hline All patients/clients are potentially infectious irrespective of their diagnostic status? & 525 & 70.8 \\
\hline Gloves should always be worn when have contact with any other body fluids except sweat? & 529 & 71.3 \\
\hline $\begin{array}{l}\text { Gown should always be worn during activities that are likely to generate splashes or sprays of blood, } \\
\text { body fluids, secretions, or excretions. }\end{array}$ & 547 & 73.7 \\
\hline A face mask, face shield, and/or goggles should be used if splashing of blood or body fluids might occur. & 563 & 75.9 \\
\hline
\end{tabular}

"Healthcare workers "Yes" response

of healthcare workers' knowledge of standard precautions. The finding revealed that overall $74.3 \%$ of healthcare workers had good knowledge of SPs. This finding almost consistent with studies done in Zambia [28] and Nigeria [29] and Pakistan [14] in which 74.4, 74.6 and $73 \%$ of study participants respectively had good knowledge of infection prevention.

The finding revealed that study participants in the current study had good knowledge of standard precautions compared to some other studies. Studies were done in Nigeria [21, 30] Addis Ababa [31], West Arsi district [18] and Gondar University referral hospital [32] showed that $37.7,65,69,53.7$ and $57.4 \%$ of HCWs had good knowledge towards SPs respectively. This difference might be accounted for by the studies done in Nigeria included study participants from a single medical center. Whereas studies from Addis Ababa and Arsi focused not only hospitals but also on HCWs from health centers. Due to the above reasons, variation in the level of knowledge among HCWs might be result.

On the other hand, the overall knowledge of HCWs of the current study was lower than from studies conducted in different areas of Ethiopia. Studies from Dessie Referral Hospital [33], Bahir Dar City Administration [34] and Debre Markos Referral Hospital [35] revealed that $95.19,84.2$ and $84.7 \%$ of study participants had good knowledge towards SPs respectively. In addition, the current study also revealed a lower knowledge of SPs among HCWs than a study from the United Arab Emirates [36] that showed $97 \%$ of the respondents were knowledgeable. This discrepancy might be due to variations in sample size, access to training and differences in self-incitation in knowing about standard precautions. Moreover, receiving up-to-date information and training will result in an increment of knowledge of HCWs towards SPs. In the current study only less than half (42.7\%) of study participants involved in SPs training programs. Such gaps might lower the overall knowledge of HCWs towards SPs in the current study.

The current study revealed that physicians were more knowledgeable than other professional groups. This finding was inconsistent with studies done in Tertiary Referral Center in North-Western Nigeria [37], Italy [38] and West Arsi [18] in which physicians were less knowledgeable than the rest of professional groups. Compared to other professional groups, a high amount of physicians were included in the current study. This might create the variation among the current study and other studies. In addition, by considering the total number of healthcare professionals in the healthcare system, physicians are more likely to participate in different pieces of training including infection prevention.

Many studies have shown that HCWs exhibited variable knowledge on standard precautions. This variation was accounted for by their years of experience [37]. Longer duration of professional experience to SPs shown to have an association with better knowledge towards standard precautions $[39,40]$. Whereas the current study showed that work experience had an inverse association with overall knowledge of HCWs towards SPs. This finding also not consistent with a study at Debre Markos referral hospital that showed work experience significantly associated with knowledge [35]. This might be due to that study participants with greater work experiences will be at risk of being exposed to chronic fatigue at work [41]. This might lead them to experience workload, physical and psychological problems that may hinder them in participating to update themselves about SPs.

Though there were no studies reported whether variations accounted for by the hospital type, the current 
Table 3 Factors associated with knowledge of healthcare workers in Amhara region towards standard precaution, 2017

\begin{tabular}{|c|c|c|c|c|c|c|}
\hline \multirow[t]{3}{*}{ Variables } & \multicolumn{4}{|c|}{ Knowledge towards Standard precaution } & \multirow[t]{3}{*}{$\operatorname{COR}(95 \% \mathrm{Cl})$} & \multirow[t]{3}{*}{ AOR $(95 \% \mathrm{Cl})$} \\
\hline & \multicolumn{2}{|c|}{ Good knowledge } & \multicolumn{2}{|c|}{ Poor knowledge } & & \\
\hline & $\bar{n}$ & $\%$ & $\bar{n}$ & $\%$ & & \\
\hline \multicolumn{7}{|l|}{$\overline{\text { Sex }}$} \\
\hline Male & 294 & 78 & 83 & 22 & 1 & 1 \\
\hline Female & 257 & 70.4 & 108 & 29.6 & $0.67(0.48-0.94)$ & $0.76(0.51-1.12)$ \\
\hline \multicolumn{7}{|l|}{ Age } \\
\hline $20-29$ & 327 & 78 & 92 & 22 & 1 & 1 \\
\hline 30-39 & 190 & 70.1 & 81 & 29.9 & $0.66(0.47-0.94)$ & $0.97(0.64-1.48)$ \\
\hline $40-49$ & 24 & 58.5 & 17 & 41.5 & $0.39(0.21-0.77)$ & $1.05(0.47-2.34)$ \\
\hline$\geq 50$ & 10 & 90.9 & 1 & 9.1 & $2.81(0.36-22.26)$ & $6.1(0.71-52.4)$ \\
\hline \multicolumn{7}{|l|}{ Marital status } \\
\hline Single & 301 & 78.6 & 82 & 21.4 & 1 & 1 \\
\hline Married & 226 & 70.6 & 94 & 29.4 & $0.65(0.46-0.92)$ & $0.86(0.57-1.29)$ \\
\hline Divorced & 15 & 62.5 & 9 & 37.5 & $0.45(0.19-1.08)$ & $1.24(0.44-3.47)$ \\
\hline Widowed & 9 & 60 & 6 & 40 & $0.41(0.14-1.18)$ & $0.65(0.17-2.46)$ \\
\hline \multicolumn{7}{|l|}{ Educational status } \\
\hline Diploma & 212 & 70 & 91 & 30 & 1 & 1 \\
\hline First degree & 323 & 79.4 & 84 & 20.6 & $1.65(1.17-2.33)$ & $1.7(1.13-2.56)$ \\
\hline Second degree and above & 16 & 50 & 16 & 50.0 & $0.43(0.21-0.89)$ & $0.8(0.35-2.21)$ \\
\hline \multicolumn{7}{|l|}{ Profession } \\
\hline Laboratory & 60 & 55.6 & 48 & 44.4 & 1 & 1 \\
\hline Nurse & 322 & 77.6 & 93 & 22.4 & $2.8(1.8-4.3)$ & $3.65(1.85-7.18)$ \\
\hline Midwifery & 72 & 62.9 & 32 & 30.8 & $1.8(1.03-3.2)$ & $1.4(0.56-3.48)$ \\
\hline Health officer & 9 & 45.0 & 11 & 55.0 & $0.66(0.25-1.71)$ & $1.8(0.57-5.87)$ \\
\hline Physician & 88 & 92.6 & 7 & 7.4 & $10.1(4.3-23.7)$ & $6.97(2.42-20.12)$ \\
\hline \multicolumn{7}{|l|}{ Service year } \\
\hline $1-3$ & 220 & 87.6 & 31 & 12.4 & 1 & 1 \\
\hline $4-6$ & 159 & 82.8 & 33 & 17.2 & $0.68(0.39-1.16)$ & $0.8(0.45-1.42)$ \\
\hline$>6$ & 172 & 57.5 & 127 & 42.5 & $0.19(0.12-0.29)$ & $0.27(0.16-0.44)$ \\
\hline \multicolumn{7}{|l|}{ Training on SP } \\
\hline Yes & 230 & 72.6 & 87 & 27.4 & 1 & $\S$ \\
\hline No & 321 & 75.5 & 104 & 24.5 & $1.17(0.84-1.63)$ & \\
\hline \multicolumn{7}{|l|}{ Hospital } \\
\hline Referral & 318 & 69.0 & 143 & 31.0 & 1 & 1 \\
\hline Zonal & 180 & 84.1 & 34 & 15.9 & $2.4(1.57-3.61)$ & $1.93(1.18-3.14)$ \\
\hline District & 53 & 79.1 & 14 & 20.9 & $1.7(0.92-3.17)$ & $1.67(0.82-3.45)$ \\
\hline \multicolumn{7}{|l|}{ Ward } \\
\hline Surgical & 79 & 56.0 & 62 & 44.0 & 1 & 1 \\
\hline Medical & 82 & 77.4 & 24 & 22.6 & $2.7(1.53-4.71)$ & $2.23(1.17-4.26)$ \\
\hline Gyn/obs & 92 & 77.3 & 27 & 22.7 & $2.67(1.55-4.6)$ & $4.27(1.97-9.23)$ \\
\hline Pedi & 57 & 80.3 & 14 & 19.7 & $3.19(1.63-6.21)$ & $2.81(1.31-6.03)$ \\
\hline OPD & 78 & 82.1 & 17 & 17.9 & $3.6(1.94-6.7)$ & $2.52(1.25-5.07)$ \\
\hline Laboratory & 77 & 71.3 & 31 & 28.7 & $1.95(1.14-3.32)$ & $3.1(1.44-6.67)$ \\
\hline Others ${ }^{*}$ & 86 & 84.3 & 16 & 15.7 & $4.22(2.25-7.91)$ & 3.8(1.89-7.88) \\
\hline
\end{tabular}

OPD Out Patient Department, $\S=$ Variables with $p$ value of $>0.2$ in bivariate analysis omitted from entering in to the multivariate model. Gyn/obs $=$ Gynecology and obstetrics and $¥=$ Ophthalmic, orthopedics, Psychiatry, Emergency and Intensive Care Unit

COR Crudes odds ratio, AOR Adjusted odds ratio, $\mathrm{Cl}$ Confidence interval 
study revealed that study participants working in Zonal hospitals were knowledgeable. Study participants from Zonal level hospitals were almost two times more likely to be knowledgeable about SPs compared to HCWs from referral level hospitals. This variation might be focus was given for HCWs from Zonal level hospitals by the regional health bureau. Concerning working units, HCWs working in gynecology/obstetrics wards were more knowledgeable. This is obvious that HCWs from this ward frequently participate in different types of upto-date training. This might help them to have good knowledge compared to other HCWs working in different wards/areas. In addition, HCWs at gynecology/obstetrics ward are more prone to expose for different body fluids. This might urge them to know about infection prevention strategies.

The Centers for Disease Control (CDC) has recommended that standard precautions be used in a better way when HCWs have adequate knowledge about them [42]. But Knowledge of standard precautions by HCWs may be influenced by different factors [43, 44]. These factors need to be addressed to implement standard precautions at all levels of healthcare facilities regardless of their staff composition, and institution type.

\section{Strength and limitation}

The inclusion of different tier of hospitals and large sample sizes of professionals from different working settings/wards was the strength of this study. As a limitation, better evidence will be built if the study was conducted using observational study methods by incorporating HCWs practice in utilizing SPs. We didn't assess on the safety measures taken from each healthcare institution. Multilevel model analysis to provide a clue on the cluster effect on such studies will have a paramount importance.

\section{Conclusion}

This study has shown that the overall knowledge of HCWs toward standard precautions was good. However, variation in their knowledge level towards SPs was appreciated across hospital and ward types. For better management of infection prevention, healthcare managers and regional health bureau should assess healthcare providers' knowledge towards standard precautions by hospital and ward types. This may lead to design a solution on how to develop a strategy in prioritizing an interventional act.

\section{Supplementary Information}

The online version contains supplementary material available at https://doi. org/10.1186/s13690-020-00509-9.

Additional file 1. Questionnaire.
Additional file 2. Sampling strategy used to carry out the study.

Abbreviations

CDC: Center for Communicable Disease Control; HAls: Healthcare Associated Infections; HBV: Hepatitis B virus; HCV: Hepatitis C virus; HCWs: Health Care Workers; HIV: Human Immunodeficiency Virus; SPs: Standard Precautions

\section{Acknowledgements}

We are very grateful to Bahir Dar University for the financial support to this study and to all study participants for their commitment in responding to our questionnaires.

\section{Authors' contributions}

WAT developed the conception of the idea, wrote the proposal, and participated in the data collection and analysis. ASK: participated in data analysis, report writing and prepared the manuscript. YW approved the proposal with some revisions and participated in the data analysis. TDT, SK, EA and SEA participated in manuscript development. All authors read and approved the final manuscript.

\section{Funding}

Bahir Dar University was the funding agent of this study.

\section{Availability of data and materials}

The datasets used and/or analyzed during the current study are available from the corresponding author on reasonable request.

Ethics approval and consent to participate

Ethical clearance was obtained from Research Ethical Review Committee (RERC) of Bahir Dar University College of Medicine and Health Sciences, and permission and support letter was secured for each respective hospital administrators before data collection. Written informed consent was obtained from each participant during data collection. The respondents were told that participating in the study has no known risks rather benefit from the study. The respondents also had given the right to refuse to take part in the study as well as to withdraw at any time during the study. No names or identifying information indicated on the questionnaires, and all subjects were assured of confidentiality.

\section{Consent for publication}

Written consent was obtained that the interview will be included in publications.

\section{Competing interests}

The authors declare that they have no competing interests.

\section{Author details}

${ }^{1}$ Department of Adult Health Nursing, College of Medicine and Health Sciences, Bahir Dar University, Bahir Dar, Ethiopia. ${ }^{2}$ Department of Pediatrics and Child Health Nursing, College of Medicine and Health Sciences, Bahir Dar University, Bahir Dar, Ethiopia. ${ }^{3}$ Department of Emergency and Critical Care Nursing, College of Medicine and Health Sciences, Bahir Dar University, Bahir Dar, Ethiopia.

Received: 29 April 2020 Accepted: 22 November 2020

Published online: 01 December 2020

\section{References}

1. Tadesse, Tenager, Fekadu Abebe, Aaron Hawkins and JP. Improving infection prevention and control in Ethiopia through supportive supervision of health facilities. Arlington, VA USAID's AIDS support tech assist Resour AIDSTAR-one, task Order. 2012;1.

2. Linda T, Débora B, Noel M. Infection Prevention Guidelines for Healthcare Facilities with Limited Resources. Maryland: JHPIEGO Corporation; 2003.

3. Office of Disease Prevention and Health Promotion (ODPHP). Why Are Healthcare-Associated Infections Important ? 2020. p. 2-3. Available from: https://www.healthypeople.gov/2020/topics-objectives/topic/healthcareassociated-infections\%0AGoal. 
4. Center for Disease Control and Prevention. Healthcare-Associated Infections ( HAls ); 2020. p. 1-5. Available from: https://www.healthypeople.gov/2020/ topics-objectives/topic/healthcare-associated-infections\%0AGoal.

5. Gebresilassie A, Kumei AYD. Standard precautions practice among health Care Workers in Public Health Facilities of Mekelle special zone, northern Ethiopia. J Community Med Heal Educ. 2014;4(3):286-91.

6. Mayank D, Anshuman M, Singh RK, Afzal A, Baronia AKPK. Nosocomial crosstransmission of pseudomonas aeruginosa between patients in a tertiary intensive care unit. Indian Pathol Microbiol. 2009;52:509-13.

7. Joseph NM, Sistla S., Dutta, T.K., Badhe, A.S., Rasitha, D, Parija S. Role of intensive care unit environment and health-care workers in transmission of ventilator associated pneumonia. J Infect Dev 201; 2014;4:282-291.

8. Federal Ministry of Health of Ethiopia. Infection prevention and patient safety reference manual for service providers and managers in healthcare facilities of Ethiopia. 2012.

9. Biniyam S, Azeb G, Desta HTG. Infection prevention practices and associated factors among healthcare workers in governmental healthcare facilities in Addis Ababa, Ethiopia. Ethiop J Health Sci. 2018;28(2):2018.

10. Geberemariyam BS. Instrument processing knowledge and practice amongst healthcare workers in Addis Ababa. Int J Infect Control. 2018;14(2):1-8.

11. Sodhi $K$, et al. Knowledge of infection control practices among intensive care nurses in a tertiary care hospital. J Infect Public Heal. 2013;6:269-75.

12. Walelegn W, Abera KFM. Point prevalence of hospital-acquired infections in two teaching hospitals of Amhara region in Ethiopia. Drug Heal Patient Saf. 2016:8:71-6.

13. Endalafer N, Gebereselassie SKB. Nosocomial bacterial infections in a tertiary hospital in Ethiopia. J Infect Prev. 2011;12(1):38-43.

14. Muhammad $\mathrm{H}$. Infectious diseases control knowledge and practice among health care workers in Bolan medical college complex hospital Quetta; 2014.

15. Vaz K, Mcgrowder D. Knowledge, Awareness and Compliance with Universal Precautions among Health Care Workers at the University Hospital of the West Indies, Jamaica. IJOEM. 2010;1(4):171-81 Available from: www. theijoem.com Vol.

16. Ethiopian Public Health Institute. Ethiopian services availability and readiness assessment ( SARA ). 2018.

17. Efifie E. Assessing the awareness and adherence to the universal safety precautions (USP) among health care workers (HCWs) in Kogi state specialist hospital (KSSH), Lokoja, Kogi State, Nigeria; 2016.

18. Geberemariyam BS, Donka GM, Wordofa B. Assessment of knowledge and practices of healthcare workers towards infection prevention and associated factors in healthcare facilities of West Arsi District, Southeast Ethiopia : a facility-based cross-sectional study. Arch Public Heal. 2018;76(69):1-11.

19. Al-mahdali G. A literature review of healthcare workers compliance to, and knowledge of standard / universal precautions. MOJ Public Heal. 2015;2(5): 156-66

20. Ethiopian HC System | Ethiopia | Health Policy, editor. Ethiopian Health System; 2015. p. 1-5. Available from: http://ethiopiahealth.blogs.wm.edu/ ethiopian-health-system/.

21. Isara AR OA. Knowledge and practice of standard precautions among health care workers in the Federal Medical Centre, Asaba, Delta State, Nigeria. Niger Postgr Med J. 2010;17(3):204-9.

22. Siegal JD, Rhinehart E, Jackson MCL. Guideline for Isolation Precautions: Standard Precautions version 1.0. health service excutive; 2009. p. 2.

23. Federal Ministry of Health Ethiopia. Infection Prevention and Patient Safety Reference Manual for Service Providers and Managers in Healthcare Facilities of Ethiopia; 2011. p. 5.

24. Tobin E, Asogun D, Odia IEG. Knowledge and practice of infection control among health workers in a tertiary hospital in Edo state, Nigeria. Direct Res J Heal Pharm Novemb. 2013;1(2):20-7.

25. Abdulraheem IS, Amodu MO, Saka MJ, Bolarinwa OAUM. Knowledge, awareness and compliance with standard precautions among health Workers in North Eastearn Nigeria. J Community Med Heal Edu. 2012;2(131). https://doi.org/10.4172/jcmhe.1000131.

26. Kaushal G, Doke P, Shah AW. An analysis of knowledge, attitude and practices regarding standard precautions of infection control and impact of knowledge and attitude of ICU nurses on self- reported practices of infection control. Int J Res Found Hosp Healthc Admin. 2015;2:79-85.

27. Alrubaiee G, Baharom A, Shahar HK, Daud SM, Basaleem HO. Knowledge and practices of nurses regarding nosocomial infection control measures in private hospitals in Sana ' a City, Yemen. Saf Heal. 2017;3(16):1-6.
28. Katowa P, Mukwato M, Ngoma MM. Compliance with infection prevention guidelines by health care workers at Ronald Ross general hospital Mufulira district. Med J Zambia. 2014;3(5):1-8.

29. AN SUA-O, Aguwa EN, UN IM. Knowledge and practice of standard precautions by health-Care Workers in a Tertiary Health Institution in Enugu, Nigeria. Niger J Clin Pr. 2018;21:149-55.

30. Ekaete T, Danny A, Ikponwonsa OEG. Knowledge and practice of infection control among health workers in a tertiary hospital in Edo state, Nigeria. Direct Res J Heal Pharmacol. 2013;1(2):20-2.

31. Admasu T, et al. Infection control knowledge, attitudes, and practices among healthcare workers in Addis Ababa, Ethiopia. Infect Control Hosp Epidemiol. 2013;34:1289-96.

32. Yazie TD, Sharew GB, Abebe W. Knowledge, attitude, and practice of healthcare professionals regarding infection prevention at Gondar University referral hospital, northwest Ethiopia : a cross - sectional study. BMC Res Notes. 2019;12(563):1-7. https://doi.org/10.1186/s13104-019-4605-5.

33. Alemayehu RAK. And SO. Assessment of knowledge and practice on infection prevention among health Care Workers at Dessie Referral Hospital, Amhara region, south Wollo zone, north East Ethiopia. J Community Med Health Educ. 2016;6(6):1-7.

34. Gulilat KTG. Assessment of knowledge, attitude and practice of health care workers on infection prevention in health institution Bahir Dar city administration. Sci J Pub Heal. 2014;2:384-93.

35. Desta M, Ayenew T, Sitotaw N, Tegegne N, Dires M, Getie M. Knowledge, practice and associated factors of infection prevention among healthcare workers in Debre Markos referral hospital, Northwest Ethiopia. BMC Health Serv Res. 2018;18:1-10

36. Sreedharan J, Muttappillymyalil JVM. Knowledge about standard precautions among university hospital nurses in the United Arab Emirates. East Mediterr Health J. 2011;17:331-4.

37. Hiyasu $\mathrm{G}$, et al. Knowledge and practices of infection control among healthcare workers in a tertiary referral Center in North- Western Nigeria. Ann Afr Med. 2016:15(1):34-40.

38. Parmeggiani $C$, et al. Healthcare workers and health care-associated infections: knowledge, attitudes, and behavior in emergency departments in Italy. BMC Infect Dis. 2010;10:35-42.

39. Kermode M, Jolley D, Langkham B. Thomas MS HW and GS (2005). Compliance with universal/standard precautions among health care workers in rural North India. Am J Infect Control. 2005;33:27-33.

40. Luo Y, He G-P, Zhou J-W, Luo Y. Factors impacting compliance with standard precautions in nursing, China. Int J Infect Dis. 2010;14:1106-14.

41. Convergence training. Fatigue at work: symptoms, Hazards, Avoidance \& Risk Management; 2020. p. 1-10.

42. Universal precautions for prevention of transmission of human immunodeficiency virus, hepatitis B virus, and other blood borne pathogens in health-caresettings. Morbidity and Mortality Weekly Report. 1988;37(24): 377-388.

43. Oliveria $\mathrm{AC}$, et al. Knowledge and attitude regarding standard precautions in a Brazilian public emergency service: a cross sectional study. Rev da Esc Enferm da USP. 2009:43(2):313-9.

44. Gershon RR, et al. Compliance with universal precautions among health care workers at three regional hospitals. Am J Infect Control. 1995;23(4):225-36.

\section{Publisher's Note}

Springer Nature remains neutral with regard to jurisdictional claims in published maps and institutional affiliations.

Ready to submit your research? Choose BMC and benefit from:

- fast, convenient online submission

- thorough peer review by experienced researchers in your field

- rapid publication on acceptance

- support for research data, including large and complex data types

- gold Open Access which fosters wider collaboration and increased citations

- maximum visibility for your research: over $100 \mathrm{M}$ website views per year

At $\mathrm{BMC}$, research is always in progress.

Learn more biomedcentral.com/submissions 